\title{
Competence In Mathematics And Academic Achievement: An Analysis Of Enrollees In The Bachelor Of Science In Actuarial Science Program
}

Robert Wamala, Makerere University, Uganda

Dyson W. Maswere, Makerere University, Uganda

Yeko Mwanga, Makerere University, Uganda

\begin{abstract}
This study investigates the role of prior grounding attained in mathematics in predicting the academic achievement of enrollees in Bachelor of Science in Actuarial Science (BSAS). The investigation is based on administrative records of 240 BSAS enrollees at Makerere University, School of Statistics and Planning in the 2007-2009 cohorts. Students' graduating Cumulative Grade Point Average (CGPA) was adopted as a measure of their academic achievement. Mathematics grade scores obtained by the students in their Advanced level (A-level) of secondary education were adopted as a measure of competence in the discipline. Academic achievement was modeled in the analysis by enrollees' characteristics and their competence in mathematics using a robust regression. The results revealed that students' CGPA increases with their A-level mathematics scores. A similar pattern is observed when the assessment is made using a combined weighted score of enrollees adopted on admission to the program. The findings confirm that 1) prior academic qualifications predict enrollees' academic achievement and 2) competence in A-level mathematics predicts success in the program.
\end{abstract}

Keywords: Academic Achievement; Actuarial Science Students; Prior Academic Qualifications

\section{INTRODUCTION}

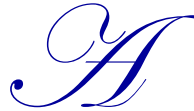

lthough the actuarial profession is one of the oldest related to economics and finance (Hickman, 2004), the actuarial science program has been introduced in many African universities and/or regions only in the recent past. In the Eastern and Central African region, the program was first introduced at Makerere University, School of Statistics and Planning (SSP), in 1972 as part of an undergraduate program leading to the award of a Bachelor of Science (BSc) degree in Actuarial Sciences. In an arrangement sponsored by the United Nations Development Programme (UNDP), 18 students who satisfactorily completed first-year studies under other University study programs and had scored good grades in Mathematics and Statistics were admitted to the program. After the stipulated two-year period of bachelor's studies, the graduates from the program were all immediately absorbed in the insurance industry, which - at the time-mainly relied on hired actuaries from abroad. The unstable political situation in the country during the 1970s made it impossible for the University to continue with the program; this was a result of the departure of core teaching staff. However, the program was re-introduced in the School of Statistics and Planning (SSP) in the academic year 2003/04 because of the growing demand for actuaries to work in the insurance industry, pension sector, and other financial institutions. Unlike in the 1970s, the program was offered as a three-year Bachelor of Science in Actuarial Science (BSAS) course. The overall objective of the program was to "equip the graduates with theoretical and practical knowledge to enable them to apply the techniques of mathematics probability, statistics and finance to solve real business problems." The key areas of study in the program include: 1) understanding basic insurance, banking, stock markets, pension scheme concepts; 2) designing insurance and other actuarial products and conducting further research; 3) conducting financial contract analysis, valuation, and investment of funds; and 4) learning to offer advice and supervisory services in insurance, pensions, and other related fields involving uncertain financial risks. 
A key challenge faced after the re-introduction of the program is the performance of enrollees assessed on the basis of their academic achievement. The faculty is becoming increasingly concerned regarding the backlog of students on the program. The competence of enrollees in terms of their prior academic qualifications is also a debatable issue. In particular, the inadequate grounding of enrollees in mathematics is argued to be the major reason for poor performance and delayed completion of studies in the program. In other words, the argument of successful performance of students who have excelled academically in the past (e.g., Alfan \& Othman, 2005; Bariez, 2002; Duff, 2004; Kyoshaba, 2009; Wamala \& Buyinza, 2013; Wamala, Omala, \& Kakumba, 2012) is put to test. In a revision of admission requirements to the program following the direct entry scheme, the department of Statistical Methods and Actuarial Sciences of SSP suggested a minimum score of Grade C in mathematics attained at the Advanced Level (A-level) of secondary education by all enrollees on the program. For diploma holders, the department suggests that a candidate must have had mathematics as a major in the program. Evidently, the entry requirements indicate the relevance of enrollees' competence in mathematics as a predictor of successful completion of actuarial studies at the University. However, barely any studies have been conducted on this aspect to provide an understanding of this issue in the country-particularly at Makerere University. Therefore, this study investigates the relevance of enrollees' grounding in mathematics in predicting their academic achievement on the program. In other words, this study provides an explanation regarding whether the SSP is fulfilling its mandate of assisting students to qualify as actuaries. The assessment accounts for possible causes of variations in academic achievement of the students due to their characteristics and prior academic qualifications.

\section{DATA AND METHODS}

The investigations are based on administrative records of enrollees for BSAS at Makerere University's School of Statistics and Planning (SSP) in the 2007-2009 cohorts. The 2007, 2008, and 2009 enrollment cohorts comprised a total of 71,92 , and 77 students, respectively. These enrollment figures represent students who were confirmed on the program based on their first year registration records.

The graduating CGPA, after the three-year stipulated period of candidature, was adopted as a measure of enrollees' academic achievement. Further, the combined weighted score of enrollees on admission to the program was adopted as a measure of their prior academic qualifications. The score is based on education outcomes or performance of enrollees in their A-level and Ordinary level (O-level) stages of secondary education. The A-level weights are obtained by multiplying each subject grade point by the relevant weighting factor and adding them up for all the subjects taken and passed. According to the 2013/2014 Ministry of Education and Sports (MoES) weighting criteria for the five public universities in Uganda (UNEB, 2012), all subjects studied at the A-level are grouped into four categories and weighted in the following manner: 1) mathematics - the essential subject-is assigned a weight of three; 2) performance in the best of two from among relevant subjects (either economics, entrepreneurship, geography, or physics) carries a weight of two; 3) desirable subjects-general paper and best of one from among chemistry, biology, and computer science-are assigned a weight of one; and 4) all other subjects are assigned a weight of 0.5 . For O-level grades, distinctions 1 and 2 carry a weight of 0.3 while credits 3-6 carry 0.2 , "Passes" 7 and 8 carry 0.1 , and a "Failure" carries a weight of 0.0 . The combined weight of a candidate is obtained by adding the O-level and A-level weights. The best candidate for the program is the one with the highest combined weight. In this study, the candidature status of the students is assessed on the basis of two outcomeseither a student has gained their Bachelor's degree by the time of the evaluation (January 2013) or not. In other words, graduating from the program by the time of the evaluation is adopted as a measure of completion.

The analysis was performed in three stages:

1. The academic achievement (CGPA) of enrollees and their characteristics (gender, nationality, year of enrollment, private-government sponsorship type, and prior academic qualifications) are presented using summary statistics and frequency distributions, respectively.

2. An assessment of candidature status (whether a student has completed studies) by enrollment cohort is made using cross-tabular analysis and associations investigated using the Pearson Chi-square Test.

3. The academic achievement of enrollees was modeled at the multivariate analysis by:

A. First, enrollees' combined weighted score and their characteristics using a Multiple Linear Regression (MLR). The appropriateness of using the MLR was investigated on the basis of the 
B. Second, enrollees' A-level score in mathematics and their characteristics using a robust regression. Employing a robust regression, adopted in the second stage of the multivariate analysis, was due to violation of the assumptions of MLR. In this case, the MLR may not be an appropriate approach for obtaining estimates; this is because the data violate some of the fundamental assumptions of MLR - outliers, non-normality, influential points, and/or missing data, etc. (Ho \& Naugher, 2000). In other words, robust regression is able to cope with or detect outlying observations in both the dependent and explanatory variables (Berk, 1990; Birkes \& Dodge, 1993; Alma, 2011). Otherwise, the estimates and/or results found using MLR could be misleading if the data do not satisfy some of the regression assumptions of an OLS model.

During the second and third stages of the analysis, associations between the variables were established at the $5 \%(\mathrm{p}<0.05)$ and $1 \%(\mathrm{p}<0.01)$ levels of significance, unless stated otherwise. The following section presents results of the analysis conducted in this study.

\section{RESULTS}

The results relate to 240 BSAS students of Makerere University, School of Statistics and Planning (SSP), in the 2007-2009 enrollment cohorts. The enrollees are characterized as predominantly Ugandan by nationality $(87.9 \%)$, males $(67.1 \%)$, and on a private sponsorship scheme $(90.0 \%)$; no major variations were noted with regard to their year of enrollment on the program-32.1\% of enrollees were in the 2009 cohort, $38.3 \%$ in 2008 , while the remainder were in the 2007 cohort.

\section{Candidature Status of the Enrollees}

The candidature status of enrollees was determined using a binary outcome-whether a student completed the bachelor's degree by January 2013. Table 1 presents a distribution of enrollees by their candidature status at the time of the evaluation.

Table 1: Distribution of the Candidature Status of Enrollees by Cohort

\begin{tabular}{|c|c|c|c|}
\hline Enrollment Cohort & \multirow{N}{*}{} & \multicolumn{2}{|c|}{ Candidature Status (\%) } \\
\cline { 3 - 4 } & & Not Completed Bachelor's Degree & Completed Bachelor's Degree \\
\hline 2007 & 71 & 47.9 & 52.1 \\
\hline 2008 & 92 & 51.1 & 48.9 \\
\hline 2009 & 77 & 58.4 & 41.6 \\
\hline$\chi^{2}=1.7, p=0.413$ & & \\
\hline
\end{tabular}

Note: Assessment is based on all BSAS enrollees registered in the period 2007-2009.

It is evident from Table 1 that there are no significant variations in the candidature status of students by enrollment cohort $(\mathrm{p}>0.05)$. In other words, the proportion of students who completed their BSAS degree does not vary significantly by enrollment cohorts. As a matter of fact, the results in Table 1 point to a considerable number of enrollees in the program staying longer than the stipulated three-year period.

\section{Academic Achievement of Enrollees}

Table 2 presents the summary statistics of the academic achievement (CGPA) of enrollees. The investigations were conducted on 114 students who graduated from the Bachelor's program by January 2013.

Table 2: Summary Statistics of the Academic Achievement of Enrollees

\begin{tabular}{|l|c|c|c|c|}
\hline Enrollment Cohort & N & Min. & Max. & Median \\
\hline 2007 & 37 & 2.67 & 4.56 & 3.45 \\
\hline 2008 & 45 & 2.52 & 4.16 & 3.21 \\
\hline 2009 & 32 & 2.73 & 4.33 & 3.26 \\
\hline Total & $\mathbf{1 1 4}$ & $\mathbf{2 . 5 2}$ & $\mathbf{4 . 5 6}$ & $\mathbf{3 . 2 8}$ \\
\hline
\end{tabular}

Note: The graduating CGPA is adopted as a measure of academic achievement. 
According to Table 2, the median CGPA of the graduates is 3.28 (range of 2.53-4.56). There are no major variations in estimates by enrollment cohort. The median figure implies a "lower second" class of degree obtained by a considerable number of graduates on the program. The findings indicate low academic achievement of actuaries regardless of their enrollment cohort.

\section{Predictors of Academic Achievement of Enrollees}

The predictors of the academic achievement of the enrollees were assessed using two models-Models I and II. In Model I, academic achievement was regressed by enrollees' characteristics (gender, nationality, enrollment cohort) and their combined weighted score adopted upon admission to the program. In Model II, academic achievement was regressed by enrollees' characteristics and grade scores attained in Mathematics at the A-level. The analysis in both models is conducted to determine the net-impact of the variables on academic achievement. The functional format of enrollees' combined weighted scores and grade scores in mathematics, variables that are continuous in nature, was determined using Multivariable Fractional Polynomials (MFP).

\section{Regression Diagnostics}

The diagnostic assessment of the academic achievement (CGPA) of the graduates on the variables adopted in the investigations for Models I and II using MLR yielded the following results:

1. Analysis in Model I
A. The homoscedasticity assumption was assessed using the Cook-Weisberg test $\left(\chi^{2}=2.89, \mathrm{p}=0.0892\right)$ and was found to be supported $(\mathrm{p}>0.05)$. In other words, an insignificant result ( $\mathrm{p}>0.05$ ) indicated a lack of heteroskedasticity.
B. The assumption of the normality of residuals was tested using the Smirnov-Kolmogorov test and was found to be supported $(\mathrm{p}>0.05)$.
C. In an assessment of the existence of outliers and/or influential points, conducted using standardized residuals, no values were found to be in excess of 3.5 or -3.5 (absolute values of the residuals were less than 3.5 ); thus, no outliers were observed in the data.

\section{Analysis in Model II}
A. The homoscedasticity assumption assessed using the Cook-Weisberg test ( $\left.\chi^{2}=7.63, \mathrm{p}=0.005\right)$ was violated $(\mathrm{p}<0.05)$. In other words, a significant result indicates heteroskedasticity.
B. The assumption of the normality of residuals was tested using the Smirnov-Kolmogorov test and was found to be supported $(\mathrm{p}>0.05)$.
C. In an assessment of the existence of outliers and/or influential points, conducted using standardized residuals, no values were found to be in excess of 3.5 or -3.5 (absolute values of the residuals were less than 3.5); thus, no outliers were observed in the data.

In light of the support for the basic assumptions, MLR was adopted in Model I-the approach was considered ideal in providing an explanation for the predictors of the academic achievement of enrollees in the BSAS program. However, a robust regression was adopted in Model II to correct for the violation of the homoscedasticity assumption. Particularly, a robust regression with Huber/White/Sandwich variance-covariance estimators was adopted in the multivariate analysis of Model II. Table 3 presents regression estimates obtained by the analysis using MLR and robust regression; thereafter, a summary of the findings is presented. 
Table 3: Regression Estimates of Academic Achievement by Enrollees' Characteristics

\begin{tabular}{|c|c|c|c|c|c|c|}
\hline \multirow[t]{2}{*}{ Characteristics } & \multicolumn{3}{|c|}{ MODEL I ${ }^{\mathrm{a}}$} & \multicolumn{3}{|c|}{ MODEL II ${ }^{b}$} \\
\hline & Coef. & Std. Err & p-value & Coef. & Std. Err & p-value \\
\hline \multicolumn{7}{|l|}{ Gender } \\
\hline Female $^{\dagger}$ & . & . & . & . & 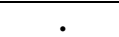 & . \\
\hline Male & 0.021 & 0.071 & 0.765 & -0.007 & 0.072 & 0.916 \\
\hline \multicolumn{7}{|l|}{ Nationality } \\
\hline Non-Ugandan ${ }^{\dagger}$ & . & & & . & . & . \\
\hline Ugandan & -0.159 & 0.102 & 0.123 & -0.123 & 0.126 & 0.331 \\
\hline \multicolumn{7}{|c|}{ Year of Enrollment } \\
\hline $2007^{\dagger}$ & . & . & . & . & . & . \\
\hline 2008 & -0.148 & 0.081 & 0.072 & -0.114 & 0.085 & 0.187 \\
\hline 2009 & -0.278 & 0.092 & 0.003 & -0.198 & 0.103 & 0.058 \\
\hline \multicolumn{7}{|c|}{ Prior Qualifications } \\
\hline $\mathrm{WT}^{\mathbf{c}}$ & 0.034 & 0.005 & 0.000 & . & . & . \\
\hline $\mathrm{MTH}^{\mathrm{d}}$ & . & . & . & 0.155 & 0.042 & 0.000 \\
\hline Cons. & 3.619 & 0.112 & 0.000 & 3.583 & 0.129 & 0.000 \\
\hline
\end{tabular}

Note: Regression estimates; where Coef. - Coefficients and Std. Err - standard Error

${ }^{\dagger}$ Represents the reference categories that were adopted

${ }^{\mathrm{a}}$ Estimates are obtained using MLR, where $\mathrm{F}=10.76, \mathrm{p}<0.001$, Adj. $\mathrm{R}$-square $=0.3199$

${ }^{\mathrm{b}}$ Estimates are obtained using a robust regression, where $\mathrm{F}=3.8, \mathrm{p}<0.001, \mathrm{R}$-square $=0.2189$

${ }^{\mathrm{c}}$ Represents the combined weighted scores adopted on admission; functional form is obtained using multivariable fractional polynomial

${ }^{\mathrm{d}}$ Represents mathematics scores obtained at the A-level; the functional form of the variable is obtained using multivariable fractional polynomial

To this end, regression results in Model I reveal significant variations in the academic achievement of enrollees by only two variables-weighted score and enrolment cohort. These results can be summarized in the following manner:

1. The association between the enrollees' combined weighted score and academic achievement was linear (see Figure 1); the student's graduating CGPA increased with their weighted score adopted upon admission to the program.

2. Enrollees in the 2009 cohort had lower graduating CGPA compared to those in the 2007 cohort. No significant variation was noted in CGPA among enrollees in the 2008 cohort compared to those in 2007.

3. In other words, the graduating CGPA is not explained by gender and nationality of enrollees $(\mathrm{p}>0.05)$.

For Model II, significant variations in academic achievement were noted only for enrollees' performance in mathematics. These results can be summarized in the following manner:

1. The association between enrollees' scores in mathematics and academic achievement was linear (see Figure 2 ); the student's graduating CGPA increased with their mathematics score obtained at the A-level of secondary education.

2. Similarly, the graduating CGPA is not explained by gender and nationality of students in the program ( $\mathrm{p}>$ $0.05)$ 


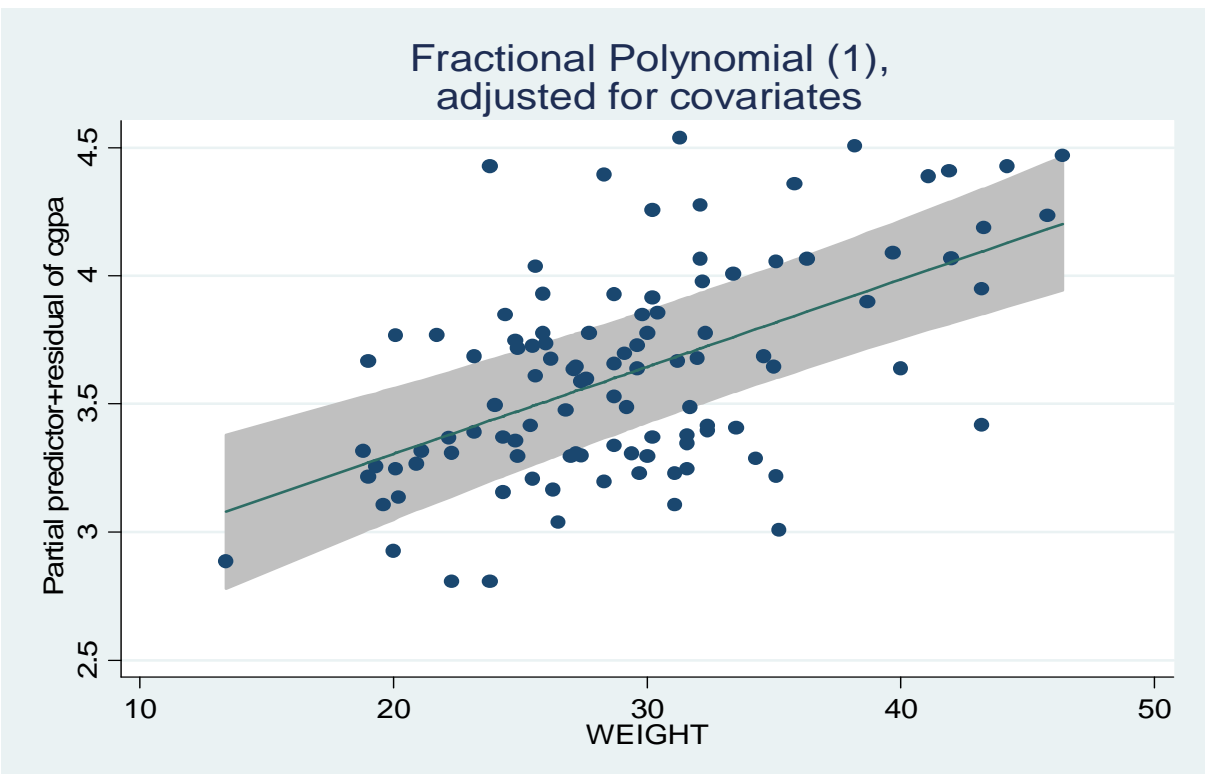

Figure 1: Relationship Between Enrollees' Weighted Score And Their Graduating CGPA

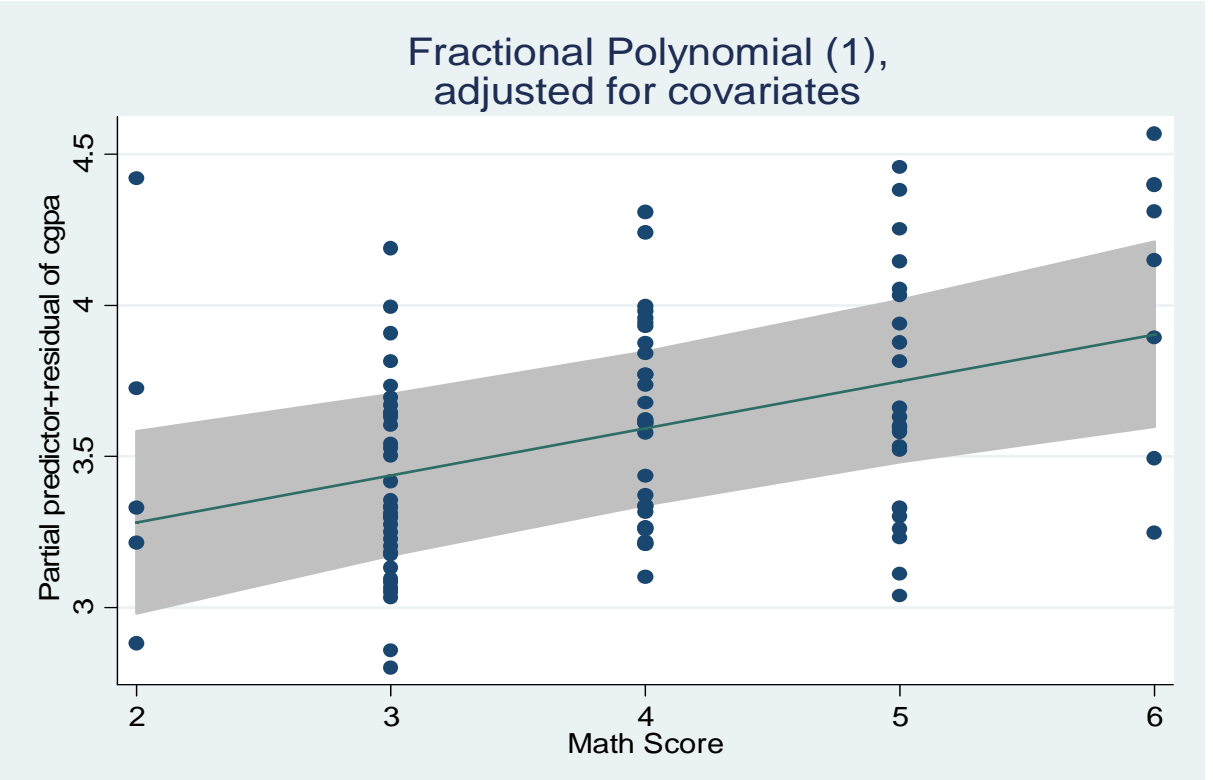

Figure 2: Relationship Between Enrollees' Mathematics Score And Their Graduating CGPA

\section{DISCUSSION}

The results reveal that the proportion of enrollees in the various cohorts who had completed their studies at the time the evaluation was conducted is low. The fact that the estimates obtained for students in the various enrollment cohorts are below average indicates a large backlog of enrollees in the system. Evidently, the noncompletion of studies of a considerable number of these students is associated with a heavy teaching and supervisory workload on the faculty (Mugimu et al., 2009). In light of a 49\% deficit in University staff (Asinja, 2012), the argument of the heavy workload on the teaching faculty functioning as a barrier to their scholarly productivity (Mugimu, Nakabugo, \& Katunguka, 2007) is highly supported. As a matter of fact, many African universities are characterized by expanding student enrollments; however, there has not been a commensurate expansion in the 
number of academic staff in many of these institutions (Tettey, 2010). Therefore, the low scholarly productivity of faculty in many African institutions and/or countries (UNESCO, 2010; Yonge et al., 2005; Muula, 2007; Adams et al., 2010; Wamala \& Ssembatya, 2013) is not surprising.

The overall median CGPA (3.28; range of 2.52-4.56) obtained in the results confirms the suggestion of low academic achievement of BSAS enrollees at the School of Statistics and Planning, Makerere University. The figure indicates a "lower second" class of degree obtained by a considerable number of graduates in the program. In an assessment of the academic achievement of law enrollees at Makerere University (Wamala, 2013), a similar pattern was noted with regard to enrollees' academic achievement in their bachelor's program. In light of the low academic achievement of actuaries and law enrollees, these findings raise questions on whether the pattern is unique to such enrollees or is applicable to all students in various academic units at the University.

With regard to the academic achievement of enrollees, the results obtained in this study add to literature supporting the role of prior academic qualifications of enrollees in predicting successful completion of subsequent academic endeavors. The consensus is that successful performance in prior studies is more likely among students who have excelled academically in the past (e.g., Alfan \& Othman, 2005; Bariez, 2002; Duff, 2004; Kyoshaba, 2009; Wamala \& Buyinza, 2013; Wamala, Omala, \& Kakumba, 2012). In this study, enrollees' prior academic qualification is assessed by their weighted score determined upon admission to the program. As stated earlier, the weighted score indicates an enrollee's competence level in undertaking studies at the University-the best candidate for the program is the one with the highest combined weighted score. The findings confirm the outcomes of O-level (UCE) and/or A-level (UACE) secondary education as measures of competence in undertaking undergraduate studies at the University. In particular, the results affirm the role of enrollees' competence in mathematics as a predictor of success in the program (e.g., Solidarity Research Institute, 2012). In the results, a high grade score obtained in A-level mathematics is associated with high academic achievement on the program. Unlike Makerere University's SSP that suggested a minimum grade score of C in mathematics at the A-level of secondary education, entry requirements by the Solidarity Research Institute (SRI) stipulate a grade score of A for all enrollees to the BSAS. In addition to the grade score in mathematics, the SRI requirements provide a minimum weighted score for enrollees to the program. However, adopting the combined weighted score as a sole measure of determining admissions to the program may not yield similar education outcomes. Take an example of two hypothetical students $\mathrm{X}$ and $\mathrm{Y}$ who obtained the following grades in mathematics, economics, and physics at the A-level of secondary education: student $\mathrm{X}$ obtained $\mathrm{E}, \mathrm{A}$, and $\mathrm{A}$ in mathematics, economics, and physics, respectively; and student $\mathrm{Y}$ obtained A, D, and D in mathematics, economics, and physics, respectively. On the basis of A-level scores, both students will have a total weight of 30; thus, both seem to have similar competence in undertaking the program, assuming other factors are constant. However, on the basis of grounding in mathematics, student $\mathrm{Y}$ is more competent for the program-evidenced by the results of this study. To this end, this study suggests adopting a combination of the combined weighted and grade scores attained in mathematics (A-level) as an ideal criterion for assessing candidates suitable for admission to the program. Nevertheless, the argument of adopting high grades in mathematics as a measure of enhancing educational outcomes in the program is highly supported.

\section{CONCLUSION}

In summary, the findings of this study confirm that 1) prior academic qualifications of enrollees are a predictor of their academic achievement in the program and 2) competence in mathematics at the A-level of secondary education is a predictor of success in undertaking BSAS studies. To this end, it is highly recommended that there be an increase in the entry requirements related to grounding in mathematics as a measure of enhancing the academic achievement of enrollees on the program. The approach is certainly argued to positively impact the quality of educational outcomes of the program.

\section{AUTHOR INFORMATION}

Robert Wamala, Ph.D. School of Statistics and Planning, Makerere University, Uganda. E-mail: rwamala@isae.mak.ac.ug (Corresponding author)

Dyson W. Maswere, School of Statistics and Planning, Makerere University, Uganda. E-mail: maswere_dw@yahoo.com 
Yeko Mwanga, Ph.D. School of Statistics and Planning, Makerere University, Uganda. E-mail: ymwanga@isae.mak.ac.ug

\section{REFERENCES}

1. Alfan, E., \& Othman, M. N. (2005). Undergraduate students' performance: The case of University of Malaya. Quality Assurance in Education, 13(4), 329-343. doi:10.1108/09684880510626593

2. Asinja, M. H. (2012). Makerere Loses Staff Over Low Pay. The Independent. Retrieved February 24, 2013 from http://www.independent.co.ug/news/news-analysis/5863-makerere-losing-staff-over-low-pay

3. Bariez, S. E. S. (2002). Analysis of the UNP College of Teacher Education graduates' performance in the Licensure Examination for Teachers (Unpublished master's thesis). University of Northern Philippines, Vigan City, Philippines.

4. Berk, R. A. (1990). A primer on robust regression. In J. Fox and J. S. Long (Eds.), Modern methods of data analysis (pp. 292-323). Newbury Park, CA: Sage Publications.

5. Birkes, D., \& Dodge, Y. (1993). Alternative methods of regression. Canada: John Wiley \& Sons.

6. Duff, A. (2004). Understanding academic performance and progression of first-year accounting and business economics undergraduates: The role of approaches to learning and prior academic achievement. Accounting Education, 13(4), 409-430. doi:10.1080/0963928042000306800

7. Hickman, J. (2004). History of actuarial profession. Encyclopedia of Actuarial Science. John Wiley \& Sons, Ltd. Retrieved from http://web.archive.org/web/20060724173339/http://www.wiley.co.uk/eoas/pdfs/TAH012-.pdf

8. Ho, K., \& Naugher, J. (2000). Outliers lie: An illustrative example of identifying outliers and applying robust models. Multiple Linear Regression Viewpoints, 26(2), 2-6.

9. Kyoshaba, M. (2009). Factors affecting academic performance of undergraduate students at Uganda Christian University. Dissertation Report. Retrieved from http://news.mak.ac.ug/documents/Makfiles/theses/Kyoshaba\%20Martha.pdf

10. Makerere University (2013). Announcement: Pre-entry Examinations for Admission to the Bachelor of Laws (2012/2013). Retrieved January 10, 2013 from http://mak.ac.ug/about/makerere-today/pre-entryexam-bachelor-laws-20122013-entry

11. Mugimu, C. B., Nakabugo, M. G., \& Katunguka-Rwakishaya, E. (2007). Exploring the factors affecting staff research output and completion rates of graduate students in Makerere University. Kampala: Makerere University.

12. Muula, A. S. (2007). Status of scholarly productivity among nursing academics in Malawi. Croatian Medical Journal, 48(4), 568.

13. Tettey, W. J. (2010). Deficits in academic staff capacity at African universities. Partnership for Higher Education in Africa (PHEA). Retrieved on October 20, 2012 from: www.foundationpartnership.org/pubs/pdf/tettey_deficits.pdf

14. UNESCO (2010). The current status of science around the world. Science Report. United Nations Education, Science and Cultural Organization (UNESCO).

15. Wamala, R. (2013). Relevance Of Prior Academic Qualifications To Predicting The Academic Achievement Of Undergraduate Students: An Analysis Of Law Enrollees At Makerere University. Journal of College Teaching and Learning, 10 (2), 143- 152

16. Wamala, R. \& Buyinza, M. (2013). Quality of education outcomes: The role of the Graduate Management Admission Test. American Journal of Business Education, 6(1), 141-147.

17. Wamala, R., Omala, S. K., \& Kakumba, U. (2012). Graduate management admission test outcomes and the academic achievement: A study on Masters of Business Administration students at Makerere University, Uganda. American Journal of Business Education, 5(6), 177-183.

18. Wamala, R. \& Ssembatya, V. (2013). Scholarly productivity in developing countries: An analysis of levels and pattern among doctoral holders in Uganda. Contemporarily Issues in Education Research, 6(2), 163172.

19. Yonge, O. J., Anderson, M., Profetto-McGrath, J., Olson, J. K., Skillen, D. L., Boman, J., Ranson Ratusz, A.,... \& Day, R. (2005). An inventory of nursing education research. International Journal of Nursing Education Scholarship, 2, Article 11. doi:10.2202/1548-923x.1095 